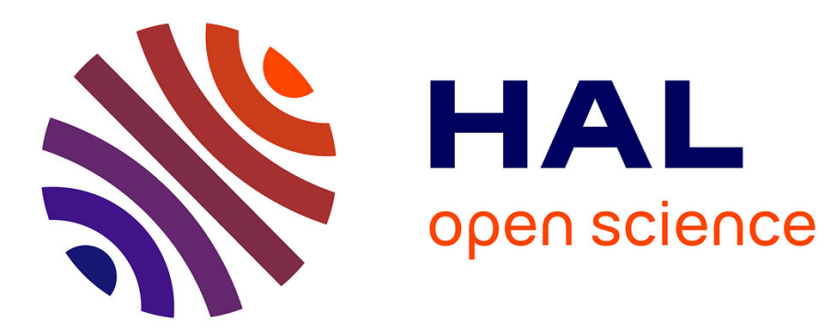

\title{
Geography, Physics and Synergetics
}

Denise Pumain

\section{To cite this version:}

Denise Pumain. Geography, Physics and Synergetics. Economic evolution and demographic change, pp.157-175, 1992, 978-3-540-56172-9. hal-01524155

\section{HAL Id: hal-01524155 \\ https://hal.science/hal-01524155}

Submitted on 17 May 2017

HAL is a multi-disciplinary open access archive for the deposit and dissemination of scientific research documents, whether they are published or not. The documents may come from teaching and research institutions in France or abroad, or from public or private research centers.
L'archive ouverte pluridisciplinaire HAL, est destinée au dépôt et à la diffusion de documents scientifiques de niveau recherche, publiés ou non, émanant des établissements d'enseignement et de recherche français ou étrangers, des laboratoires publics ou privés. 
Denise Pumain (Université Paris I, I.N.E.D.)

\section{Abstract}

Geography has a long tradition of borrowing concepts and mathematical models from physical sciences. Applications of the gravitational model for the analysis and prediction of spatial interactions are the best known examples, since about the middle of the XIXth century. However, dissatisfaction with the terms of the analogy led geographers to substitute to the mechanical metaphor a broader and more vague organicist metaphor, which remained typical of the French school of geography until the 1950's. Today, many properties of synergetics are thought very attractive by geographers as a general framework for reflexion and modelling. Geographical space is often conceptualized as the result of interactions among social actors, which produce a hierarchical structure, with several levels of organization. With a better understanding of individual behaviour, dynamic models can be conceived, for instance for cities or regions. Therefore, a closer collaboration of physicists and geographers is needed. 


\section{Introduction}

Besides the happy event and the long friendship explaining our meeting in a fully deterministic way, there are many other good reasons for recalling the links between geography and physics. Actually the mutual history of those two disciplines is already too long to be summarized in a short paper. Since the time where they collaborated in the same person, who could call himself together a physicist and a geographer, (and also an explorer in both senses!), like a Pierre-Louis Moreau de Maupertuis measuring the Terrestrial meridian, the relationships have been constant and diverse.

Since about the middle of the XIXth century, when it emerged as an institutionalized discipline, geography has a long tradition of borrowing concepts and mathematical models from physical sciences.

Geography is closer to physics than any other social science, because it deals with the material inscription of human societies on the surface of the earth. However, geography is close to physics not only because of its links with "geophysics" or because of the existence of a branch of specialization called "physical geography", mainly dealing with natural environment, including geomorphology, climatology and biogeography, using plate tectonics or physical models of turbulence and remote sensing methods, and today interested in the analysis of geosystems and "global change".

I would preferably stress the importance of physics for human geography. I shall first recall how physical analogies, especially with gravitational models of newtonian mechanics, have been used for a mathematical formalization of aggregated human interactions in geographical space. I will then enumerate a few properties of geographical space and of geographical structures which are today thought of as reasonable grounds for developing analogies with the models built in the framework of synergetics.

\section{Models of geographical interactions}

\section{1-1 Polarization and gravitation}

Among the first borrowings of physical concepts by geographers have been rather fuzzy analogies coming from magnetism and from astronomy. The organization of the flows of traffic and of the transportation infrastructures in a radial form around centers of attraction has been described since a long time as a polarization phenomena. This word is still used as a geographical concept for defining the power of concentration of the direction of the flows by a specific place acting as a focus, a center in the geographical space: for instance at a lower scale a retail shops polarizes the journeys of its customers, or a farm centralizes the various movements which are necessary for the production in the surrounding fields; at a higher and aggregated level, a city is supposed to exert a power of polarization on a large share of the communications around it (figure 1). 
The borrowing to magnetism has however never gone beyond the simple use of the word and the level of the analogy. The close concept of a "field" has received some geographical semantic content, but with less references to magnetism than to gravitation. On the contrary, the analogy between urbanism and astronomy, between the spatial pattern of cities of various sizes and the systems of stars was promised to richer developments. First formulated perhaps by Le Maistre in his famous text "La Métropolitée" (1682) this idea appears many times during the XIXth century, for instance in writings by $E$. Reclus (1895) or E. Levasseur (1889) : "les villes, étoiles de première grandeur, ont avec les autres ce caractère commun qu'elles exercent en général sur la population rurale une puissance d'attraction qui est proportionnelle à la masse de leur propre population".

The most complete formulation of a "system of cities" with not a superficial analogy with a solar system but a real theoretical transposition to geography, including the explicitation of specific geographical interactions, was made by the Saint-simonian engineer, Jean Reynaud (1841). He is the real inventor of the "central place theory" with all its fundamental principles including its geometrical formalization of market areas as hexagons. His work was rediscovered recently by M.C. Robic (1982). Kohl (1841) is perhaps the first who draw models of the planetary systems of cities with circular orbites and who connected it with the transportation patterns. As soon as 1897, P. Meuriot tested Levasseur's law on European agglomerations. But the first applications of derived mathematical formulations came after the observations about migration flows : the "laws of migration" edicted by Ravenstein (1885 and 1889) were tested by A.F. Weber on the evolution of cities during the nineteenth century (1899). The first operational use of the model was intended for the computation of the probable number of customers for a retail center and of the limit between the trade areas of two retail centers (Reilly, 1931).

\section{1-2 Reformulations of the gravity model}

Geographers are now familiar with Newton's formula, generally called "gravity model", that they normally use for predicting the migration flows Mij, or many other kinds of spatial interactions (number of railway- or air-passengers, number of telephone calls, number of customers etc...) between two geographical units $i$ and $j$ (those may be cities, regions, supermarkets and residential areas...) separated by a distance dij, in the general form:

$\operatorname{Mij}=\mathrm{k}$ Pi Pj dij exp $(-\mathrm{a})$

or $\operatorname{Mij}=k \operatorname{Pi} \operatorname{Pj} \exp (-b \operatorname{dij})$

where $\mathrm{Pi}$ and $\mathrm{Pj}$ are the repective "masses" of zones $i$ and $j$ (usually measured by population size, or total floor space or turnover) and $\mathrm{a}, \mathrm{b}$ and $\mathrm{k}$ parameters to be estimated. 
However called "social physics" as it was first mentioned by Quételet (1830) and rediscovered later by the astronomer Stewart (1947 and 1948) those first applications were in many respects a "geographical physics". The main issues where about potential and forces driving migration flows towards cities according to a gravitational model. Stewart found many strong correlations between various interactions between places (such as traffics, migrations or communications) and the expression $\mathrm{k}$ $\mathrm{Pi} \mathrm{Pj} / \mathrm{dij} 2$. Recently, de Vries (1984) used the concept of population potential to test the ideas of $F$. Braudel about the shifting of the centers of urban power from southern to northwestern Europe between 1500 and 1800 (figure 2).

If many other applications, like for instance among the first ones the computations made by Reilly (1931) in his model of retailing, kept rather close to the original newtonian formula, it was noticed very early that there was no reason to maintain in the applications a deterrence effect using the square of the geographical distance. A more general interpretation should be given to this parameter as figuring the intensity of "friction" of distance, or a sensitivity to displacement, and it was argued that an adjusted exponent would in most cases give better experimental results (Isard, 1956).

Dissatisfactions with the other terms of the analogy appeared also rather early. The quantities measuring the "masses" of the centers were discussed : they should correspond to an effective power of attraction explaining the intensity of the flows. Instead of using population only, weightings by income levels or wages were proposed and, in models for retailing, floor space of shopping centers. Similar transformations occured for the measures of distance : the "physical" distance as measured using geographical coordinates is not always very important, more significant is the real uneasiness of access as measured by cost or time spent in transportation; topological distance is sometimes an efficient measure when flows are using specific transportation networks. In other cases "social" distance, as measured by differences in social status, income, or cultural habits, linguistic practices or ethnic origins is more relevant. An interesting interpretation of the role of the distance for migrations was given by stouffer (1940) as a proxy for the number of "intervening opportunities" or possible alternative locations, which may grow in average like the square of the radius of a circle surrounding the migrant.

There were doubts also about the validity of the mathematical formulation of the gravity model. Despite a rather obvious probabilistic interpretation of the mass product PiPj (as the conditional probability of finding an individual in location $j$ at time $t+1$, knowing that he was at location $i$ at time $t$ ), other mathematical models have been proposed to derive migration flows, for instance by $W$. Tobler (1979), estimating a pull factor $M_{j}$ for region $j$ and $a$ push factor $E_{i}$ for region $i$ as follows:

$M i j=(E i+M j) \operatorname{dij} \exp (-a)$ 
the additive form has a straightforward interpretation as a "push-pull" model, it may give similar, sometimes better results than the multiplicative one, it has not more and not less justification.

\section{1-3 The entropy maximizing approach}

Because "the geographical regularities which gravity models describe is statistical by nature" (Alonso, 1986), the approach of statistical mechanics has been preferred to the Newtonian mechanics. A. Wilson (1969) substituted to the gravity model a formulation derived from information theory by using the entropy maximization principle. It predicts the migration flows Mij between geographical units $i$ and $j$, characterized by their total population (or residents on one side and jobs on the other...) as origins $O i$ or as destinations $D j$, with the following formula:

\section{$\operatorname{Mij}=A i$ Bj Oi Dj $\exp (-\mathrm{bcij})$}

where $\mathrm{b}$ is a parameter of sensitivity to the transportation cost $c i j$ from $i$ to $j$ and $A i$ and $B j$ are scaling terms. The constraint which is necessary to derive this equation is that there is a maximum total cost $C$ which is the sum of all cij. This quantity can receive an interpretation as a constraint coming from the higher organizational level, the system of cities which one single city is belonging to and where a competition between cities occurs. A difficulty remains for measuring it. But the maximisation of entropy has here no "physical" nor phenomenological interpretation (Willekens, 1980), it merely corresponds to the possibility for predicting a set of flows, adding minimum information to the data about population configuration. It can also be discussed whether any observed distribution of geographical interaction flows should maximize some principle and why the observed system should be in a state of equilibrium.

Researches today underline the need for a better specification of spatial interaction and to view the interaction process as an integrated phenomenon, composed not only of the usual mass and distance effects, but also of the elements of accessibility and competitiveness in flows and of feedbacks among the various interactional effects in human populations (Haynes, Fotheringham, 1984).

However there is still a contradiction in geography between the rather encouraging success of the gravitational models in operational applications, especially for migration analysis and retail trade or traffic previsions, and the lack of really consistent theoretical justification for the analogy. The analogy has no real grounds in geographical theory, neither in the properties of geographical space nor in the characteristics of the spatial behaviour of the individuals. Specific features are often let aside as significant "rediduals" by the model. The necessity of complicating the model to include meaningfully those effects and the lack or really explanatory power is frustrating. 


\section{1-4 About men and particles}

The most difficult aspect in transferring concepts from physics to geography occurs at the micro level, where human persons are more or less supposed to behave as chemical molecules or physical particles. For instance there is nothing to be learned about social segregation by assimilating it to the repulsive effect of positive or negative electric charges. On the other hand, there is a risk that such a representation would lead to consider social segregation as a "physical" phenomena, in the sense of "natural" and consequently "normal", without any possible correction, whereas it is actually a cultural product, which can therefore be modified. Here is certainly the highest point of sensitivity to the risks of using analogies between physics and social science. However models coming from electronics may help to simulate the effects of a more or less intense repulsion between social groups, and to test the effects of parameters values as prices of land or housing, rates of construction of social housing... on residential migration of a segregative type. The model would be operational in this case but it is not a theoretical one.

To be useful at the theoretical level, a real efficient transfer of a physical model to geography should explicitly integrate the characteristics of the socio-spatial behaviour of the individuals. As in other social sciences, the direct transposition of macro-variables like temperature, pressure..., has never given good results, even in the cases when, according to some general system theory principles, all measurements where converted into energy. More interesting is to develop analogies about the processes which are relating micro and macrovariables, because they provide a formal explanation for the dynamics and mathematical models for computation.

The rediscovery by natural sciences of the possibility of longrange correlation and cooperative phenomena between particles in open systems far from equilibria and furthermore their explicit integration into mathematical models is the main reason for the success of the "self-organization" idea in the social sciences today. Old ideas that social scientists did not know how to formalize are taken into account, and the reintegration of some human, anthropological features into mathematical models is recognized and accepted as a useful contribution of physicists to social sciences.

\section{Models of geographical structures}

The difficulty of modeling human spatial interactions may partly explain why geographers have rather soon let aside the "mechanistic metaphor" when discussing their main concepts of geographical structures, as the concept of region. At the beginning of the Xxth century, however informed of the developments of thermodynamics (as attested for $\mathrm{J}$. Bruhnes by M.C. Robic (1989) for instance) they did not borrow concepts from this field before the 1960's (Curry, 1964) and developped instead a provisionally more satisfying "organicist analogy", 
which prevailed during the whole first half of Xxth century. That analogy remained howewer qualitative and inspired a kind of suspicion against any mathematical modeling, which was especially strong within the French school of "regional geography" until the 1960's. A new interest for quantification and transfer of concepts from natural sciences to geography appeared first during the 1940's and 50's in America and came back to Europe through Great Britain (see P. Haggett, 1991). The developments of that trend are too numerous and too diverse to be summarized here. Interesting is the fact that the most recent transfer of concepts from dissipative structure theory (Prigogine, Stengers, 1979) and from synergetics (Haken, 1977) to social sciences and geography first appeared in Europe (for instance, Allen, 1978, Weidlich, Haag, 1987). As suggested by W. Weidlich (1991, p. 6) we would like to stress how some "adequate system concepts" stemming from geographical models and theories may be combined with "universally valid synergetic concepts" for founding "indirect structural analogies between systems of nature and society".

\section{2-1 The relativity of geographical space}

The first formalizations of geographical space were made within the framework of the classical mechanic using a concept of continuous, isotropic space with euclidean metrics (Bunge, 1962; Beguin, Thisse, 1979). But geographical space is essentially discontinuous and anisotropic. This is due to the natural heterogeneity in the distribution of slopes, rivers, types of soil, climates and so on at the surface of the earth, but it also has anthropological grounds (Moles, 1972; figure $3)$. For instance, the perception of distance is not a linear but a logarithmic function of physical distance from the observer. The aggregation of those individual perceptions and of subsequent behaviours shows revealed preferences or mental maps (Gould, 1985) with significant directional biases and spatial discontinuities.

Instead of an absolute conception of space as a framework containing human activities, a relative conception is now prevailing, where places are located after their geographical situation, as measured from their various possibilities of interaction. Combination of perception, valuation of places and of inequal availability of communication facilities gives rise to specific properties of the geographical space (Harvey, 1990). When it is described after the variations in accessibility among a set of places, it is most of the time no longer described by using euclidean metrics but for instance by riemanian metric (Tobler, 1976; Muller, 1983). Various anamorphosis try to figure the configuration of interaction fields (functional or cognitive spaces), which substantially differ from the classical map projections (Rimbert, 1991).

\section{2-2 Fractality of geographical space}

As well as for the structure of material in physics, the scale of observation is crucial for the description of the type of structure within geographical space. One of the first to have tried to put it in a systematic way may be Philbrick (1957). He 
noticed that the structure of geographical space is made of an alternance of polarized and homogeneous structures : for instance at a micro geographical level a farm organizes around it the space of the fields by polarizing the movements for cultivation. At a higher scale, a set of farms of roughly the same economic orientation forms an homogeneous small agrarian locality, whose movements for access to services are polarized by a village center. Several villages of the same kind form again at a higher level an homogeneous agrarian region, which may be polarized by a town acting as a higher-order service center and as a market for agricultural products. Even if all regions do not always exhibit such a regular nested pattern alterning homogeneity and polarization, the essential property of geographical space is to define a specific type of structure depending on the scale of observation. The hierarchical structure revealed by central place theory is another illustration of this fact (figure 4). The analogy with physical systems having fractal properties has been noticed early (Woldenberg, Berry 1967; Chorley, 1964) and further progresses in the direction of this analogy are made explicit now (Frankhauser 1991).

\section{2-3 space-time convergence}

At least since the development of railways networks, the idea that geographical space is contracting over time, according to progresses in the efficiency of communication technologies, has become popular. It was illustrated in a descriptive way for instance by J. Bruhnes (1910), as "the modification of the relations between parts of the earth by acceleration of the speed which is necessary to cover the same distances" (figure 5). A more elaborated formulation of this process was given by Janelle (1969) under the expression of "spatial reorganization". Historians like H. Pirenne had noticed the importance of improvements in transportation means in the revival of cities of the early Middle Ages. A. Anderson (1986) extends this idea and finds in historical times (between 1000 and 2000 A.C.) four "logistical revolutions", that is, transformations of the techniques which allow to move goods, people, capital and information, which had significant effects on geographical structures.

Even if the historical increase of the speed of transportation means was not homogeneous, neither continuous, it has been rather monotonic. The effect of space-time contraction due to the acceleration of the speed of communications is not only to increase the range and frequency of human mobility. It also has indirect consequences on the relative situation of places, and on the scale of observable geographical structures. An obvious example is given by the evolution of the spatial structure of settlement systems. From a scattered distribution of small villages, a few were selected, on a "self-organizing" basis, to act as market centers. Only a few from those were able to grow and to concentrate more and more population, and to become large towns and cities, according to the increasing speed of movements, by walking, riding, using wagons, railways, planes or TGV trains. During this process, there was of course an increase in total population, number and size of cities, but 
the relative number of the largest centres has decreased as the spatial range of their activities has increased: the smallest centres were short-circuited, the relative concentration of the population in the largest cities was increasing and the urban hierachy was simplified "from below" (Pumain, 1982, GuérinPace, 1990).

Such a systematic modification of the space of reference during the course of time has to be taken into account into models, for instance when simulating the development of regional or urban systems, but the transfer of possible formalizations from physics has not yet been conducted.

\section{2-4 The example of urban hierarchies}

In some cases, concepts and models from physics have been transferred to solve a geographical problem but, despite many efforts, without much success. The tentatives for explaining the statistical shape of the distribution of city sizes in a regional or more often national set of cities provide a good example.

Cities belonging to the same region or to the same country are strongly differentiated according to their size. The size distribution is highly skewed, with many small towns located close to each other, a smaller number of more distant mediumsize cities and only a few very large cities which are located in average far from each other. The number of cities is roughly related to their size through an inverse geometrical progression, the distribution is similar to a Pareto function or to a lognormal distribution (Gibrat, 1931). The distribution remains remarkably stable through time (figure 6).

Several explanations have been put forward to explain such a distribution. It was first considered as expressing an equilibrium. Zipf (1949) considered the "rank-size rule" as an equilibrium between two counterbalancing forces, a "force of concentration tending to concentrate people and activities on the same place of production and consumption in order to avoid transportation costs, and a "force of diversification" locating production and consequently consumption in the vicinity of the natural ressources in exploitation, which are rather dispersed. His explanation of why the two forces equilibrate and produce the perfect regular size distribution of cities was however not really argued.

Tentative explanations of city size distribution as the most probable state of of an urban system are not convincing either. Borrowing the concept from statistical mechanics, Berry and Garrison (1958) have suggested without demonstration that the Pareto distribution would correspond to a state of maximum entropy within the urban system. Curry (1964) has derived a skewed distribution of city sizes from the principle of entropy maximisation (in the sense of information theory) in a process of allocation of individual cities among the various possible city sizes. Many weaknesses have been found however in his interpretation: the theoretical resulting distribution is rather different from the observed ones (Haran, Vining, 1973), 
the model supposes a closed urban system (Chapman, 1970), and the explanation is only shifted from the size distribution to the constraints which have to be defined to get it as a result of the process (Pumain, 1982).

Many other tentative explanations have related this distribution to deterministic (Steindl, 1968) or to stochastic (Simon, 1955, Gibrat, 1931) processes of growth distribution within a set of cities. Some insights have been gained about the urbanization process by testing those ideas on sets of empirical data (Robson, 1973, Pumain, 1982, Guérin-Pace, 1990) but there is no real agreement about interpretations. For some authors, randomness in the growth process still means that the size distribution corresponds to maximum entropy and to disorder, whereas for others the law reveals an ordering principle in the urban system (Frankhauser, 1991), and some of them think that it may be considered as an attractor in a dynamic process of urban growth (Haag, 1992).

All those transfers of ideas are justified since, like in the case of gravity models, many mathematical models can be adjusted to the observations, so regular they are. But all those transfers stumble against the same problem already encountered by Quandt (1964) and Robson (1973), which is an overidentification of the models. The distribution of city sizes can receive as many explanations as any highly skewed distribution, but never those mathematical models would explain why this kind of distribution is observed precisely in the case of cities. The statistical distribution of city sizes let aside the spatial configuration of the urban system, which is an essential component of its dynamics. It is only by integrating the geographic specificity of a set of cities that a mathematical model may have a chance to bring something new to the knowledge of urban systems.

This should lead to careful explicitation of geographical interactions. Models from the synergetics are promising because they deal precisely with the emergence of spatial structures. The modeling of individual spatial behaviours and of their effects in the building of geographical configurations is still at its beginning however.

\section{2-4 Processes and geographical forms}

Most of geographers have abandoned the rather loose organicist metaphor and use instead a systemic framework for explaining the organization of geographical space. They have noticed that among all possible spatial configurations, a small number of spatial forms were recognizable at various spatial scales and in many different socio-economic or cultural contexts. $R$. Brunet (1980) suggested that those elementary forms, that he calls "chorèmes", could be articulted as words in a language (figure 7). Progresses have still to be made in the dynamic interpretation of such observations. A better knowledge about the genesis and the evolution of the limited number of observed geographical configurations could be gained from the use of dynamic models from the synergetics. 
Research has already started in this direction, and several different approaches are used to generate geographical configurations and to study their dynamics. Their number is already too large to review them all, references can be found for instance in Wilson, 1981, Dendrinos and Sonis, 1990, Weidlich, 1991, Rosser, 1991... or in the specialized journal "Socio-spatial dynamics".

Parallel to this theoretical research, there may be something interesting to hold from the first applications of models of dissipative structures or even of simple models of the preypredator type to the evolution of geographical configurations. They have revealed the scarcity of bifurcations and the quasi absence of chaotic behaviour in geographical systems (Dendrinos, Mullally, 1985, Pumain, Sanders, Saint-Julien, 1989). The use of the physical analogy is a way for rediscovering the regulations which intervene in human societies for avoiding catastrophic or erratic issues. The effects of cooperative behaviour and of learning processes are for instance reintroduced in models which are designed for controlling the evolution of large computing systems (Huberman, 1988). Especially when creativity and innovation are considered, one should carefully explore which individual properties are relevant for explaining the geographical configurations at the upper levels. In this respect, it seems that a minimum consideration of variety among a human population is always necessary (Allen, McGlade, 1987).

\section{Conclusion}

It may be interesting to notice that the time lag between the formulation of a model in physics and its use in geography has dramatically decreased : about hundred and fifty years for gravitation, hundred years for thermodynamics, fifty years for quantic ideas and only ten years for synergetics...

Synergetics may become in the next decades the dominant metaphor situating the discourses about the dynamics of geographical forms. Warranting innovation today, it may become conservative if a true analytical transfert is not realized and if the validity of the notions which are used is not enough checked in the context of geographical theory and observations. This can only be achieved by a close cooperation between physicists and geographers. 


\section{REFERENCES}

Allen P. 1978 - Dynamique des centres urbains. Sciences et Techniques, 50, 15-19.

Allen P.M. McGlade J.M. 1987 - Evolutionary Drive: the Effect of Microscopic Diversity, Error Making, and Noise. Fondations of Physics, 17, 7, 723-738.

Alonso W., 1986 - Gravity models. Harvard University, Center for Population Studies, Discussion Paper 86-9, 7 p.

Beguin H. Thisse J. 1979 - An axiomatic approach to geographical space. Geographical Analysis, 325-341.

Berry B.J.L. Garrison W.L. 1958 - Alternate Explanations of Urban rank-size relationships. Annals of the Association of American Geographers, 1, 83-91.

Brunet R. 1980 - La composition des modèles dans l'analyse spatiale. L'Espace Géographique, 4.

Bunge W. 1962 - Theoretical Geography. Lund Studies in Geography, serie $C$, 1 .

Chapman G.P. 1970 - The application of information theory to the analysis of population distribution in space. Economic Geography, 2, 317-331.

Chorley R.J. 1964 - Geography and analogue theory. Annals of the Association of American Geographers, 127-137.

Curry L., 1964 - The random spatial economy. Annals of the Association of American Geographers, 138-146.

Dendrinos D. Mullally H. 1985 - Urban Evolution. Oxford University Press.

Dendrinos D. Sonis M. 1990 - Chaos and socio-spatial dynamics. New York, Springer Verlag.

Frankhauser P. 1991- Aspects fractals des structures urbaines. L'Espace Géographique, 1, 45-69.

Gibrat R. 1931 - Les inégalités économiques. Paris, Sirey.

Gould P. 1985 - The geographer at work. London, Routledge..

Guérin F. Pumain D. 1990 - 150 ans de croissance urbaine. Economie et Statistique, $230,5-16$.

Haag G. 1992 -

Haggett P., 1990 - The geographers'art. Oxford, Blackwell.

Haken H., 1977 - Synergetics, an introduction. Berlin, Springer. 
Haran E.G.P. Vining D.R. 1973 - On the implications of a stationary urban population for the size distribution of cities. Geographical Analysis, 4, 194-200.

Haynes K. E. - Fotheringham A.S., 1984 - Gravity and Spatial interaction Models. Beverly Hills, CA, Sage, Scientific geography series 2 .

Huberman B.A. ed 1988 - The Ecology of Computation. New York, North Holland.

Isard W., 1956- Location and space economy.Cambridge, MIT Press.

Kohl J.H. 1841 - Der Verkher und die Ansiedlungen der Menschen in ihrer Abhängigkeit des Gestaltung der Erdoberfläche.

Dresden, Arnold.

Le Maistre 1692 - La Métropolitée

Levasseur E., 1889-92 - La population française, 3 vol..

Muller J.C. 1983 - La cartographie des espaces fonctionnels. L'Espace Géographique, 2, 142-152.

Philbrick A.K. 1957 - Principles of Areal Functions of Organization in Regional Human Geography. Economic Geography, 299-336.

Prigogine I., Stengers I., 1979 - La nouvelle alliance. Paris, Gallimard.

Pumain D. 1982 - La dynamique des villes. Paris Economica.

Pumain D. Sanders L. Saint-Julien T. 1989 - Villes et autoorganisation. Paris, Economica.

Quandt R.E. 1964 - Statistical discrimination among alternate hypothesis and some economic regularities. Journal of Regional Science, 2, 1-23.

Quetelet, 1830

Ravenstein E.G., 1885 and 1889 - The laws of migration. Journal of the Royal Statistical Society, 48, 167-235, and 52, 241-305.

Reclus E., 1895 - The Evolution of Cities. The Contemporary Review, 67, 246-264.

Reilly W.J., 1931 - The law of retail gravitation. New York, W.J. Reilly Co.

Reynauld J., 1841 - Villes, in l'Encyclopédie Moderne, Paris, Gosselin, VIII, 670-687.

Rimbert S. 1991 - Carto-graphies. Paris, Hermès.

Robic M.C., 1982 - Cent ans avant Christaller, une théorie des lieux centraux. L'Espace Géographique, $\mathrm{n}^{\circ} 2$, 5-12. 
Robic M.C. 1989 - Perspectives temporelles sur l'émergence de quelques concepts de la géographie urbaine française. Sistemi Urbani, 3, 225-239.

Robson B. 1973 - Urban growth, an approach. London, Methuen.

Rosser J. B. 1991 -

Sanders L. 1992 - Systèmes de villes et synergétique. Paris, Economica.

Simon H. 1955 - On a class of Skew Distributions. Biometrika, $425-440$.

Steindl J. 1968 - Size distributions in economics, in

"International Encyclopedia of the Social Science, vol. 14

(Silks ed.) New York, Macmillan.

Steward J.Q., 1947 - Suggested principles of "social physics". Science, 106, 179-80.

Steward J.Q., 1948 - Demographic gravitation : evidence and application. Sociometry 1, 31-58.

Stouffer S.A., 1940 - Intervening opportunities : a theory relating mobility and distance. American Sociological Review, 5, 845-867.

Tobler W. R., 1976 - The geometry of Mental Maps, in: Golledge R.G. ed, Spatial Choice and Spatial Behavior, Colombus, Ohio State University Press, 69-81.

Tobler W., 1979 -

de Vries J. 1984 - European Urbanization. London, Methuen.

Weber A.F. 1899 - The growth of cities in nineteenth century. New York, Macmillan.

Weidlich W., 1991 - Physics and social sciences - the apporach of synergetics. Amsterdam, North Holland, Physic Reports, 204, $1,163 \mathrm{p}$.

Weidlich W. Haag G., 1987 - A dynamic phase transition model for spatial agglomeration processes. Journal of Regional Science, 529-569.

Willekens F., 1980 - Entropy, multiproportionality adjustments and analysis of contingency tables. Sistemi Urbani, 2, 171-201.

Wilson A., 1969 - Notes on some concepts in social physics. Papers of the Regional Science Association, 22, 159-193.

Wilson A., 1971 - A family of spatial interaction models and associated developments. Environnement and Planning, 3, 255282 . 
Wilson A. 1981 - Catastrophe theory and bifurcation:

applications to urban and regional systems. London, Croom Helm.

Woldenberg M.J. Berry B.J.L. 1967 - Rivers and Central Places:

Analoguous Systems? Journal of Regional Science, 129-139.

Zipf G.K., 1949 - Human Behaviour and the Pincipe of Least

Effort : an Introduction to Human Ecology. Cambridge, AddisonWesley. 
Figure 2 Potential of European urban population

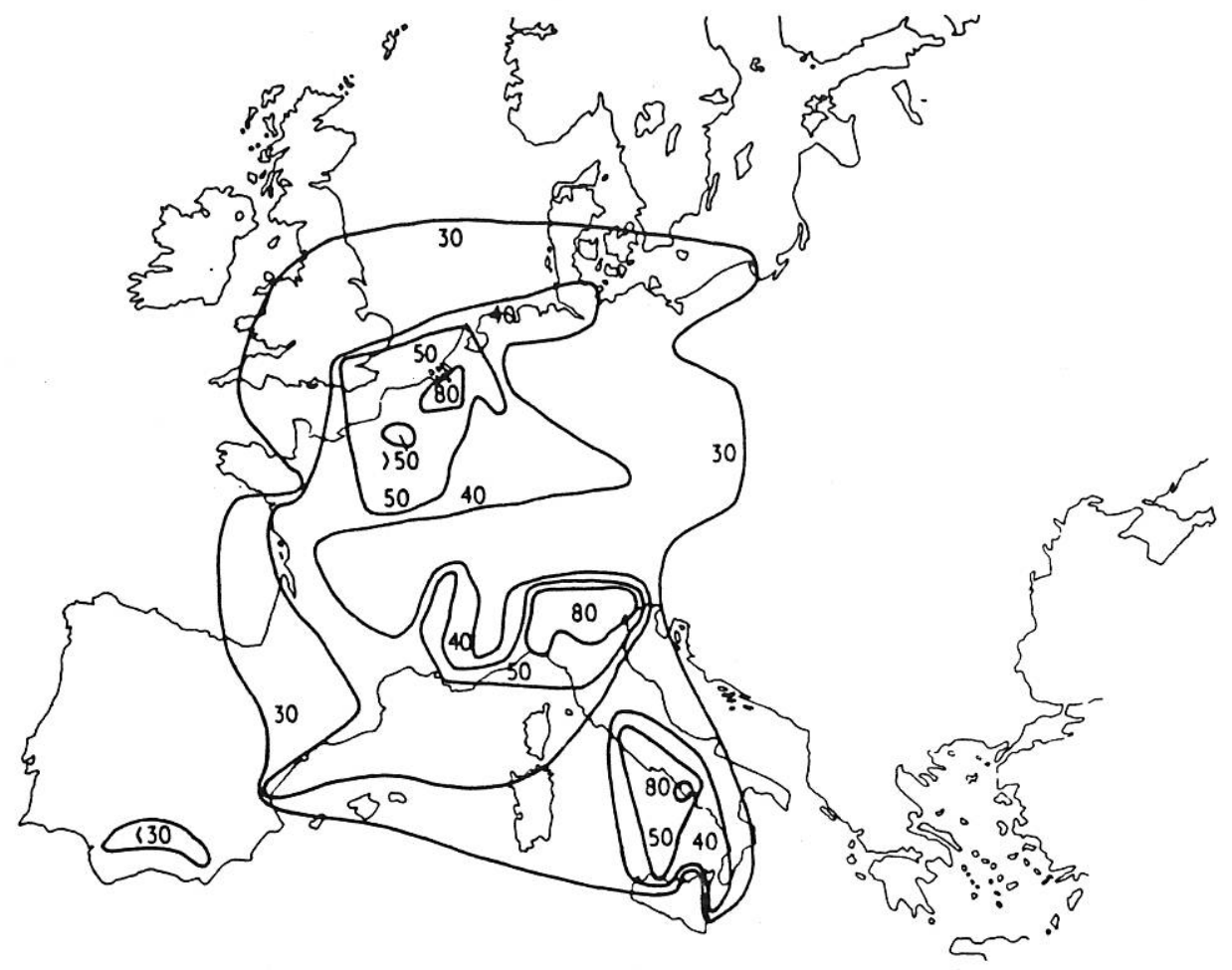

Urban potential in Europe, 1500

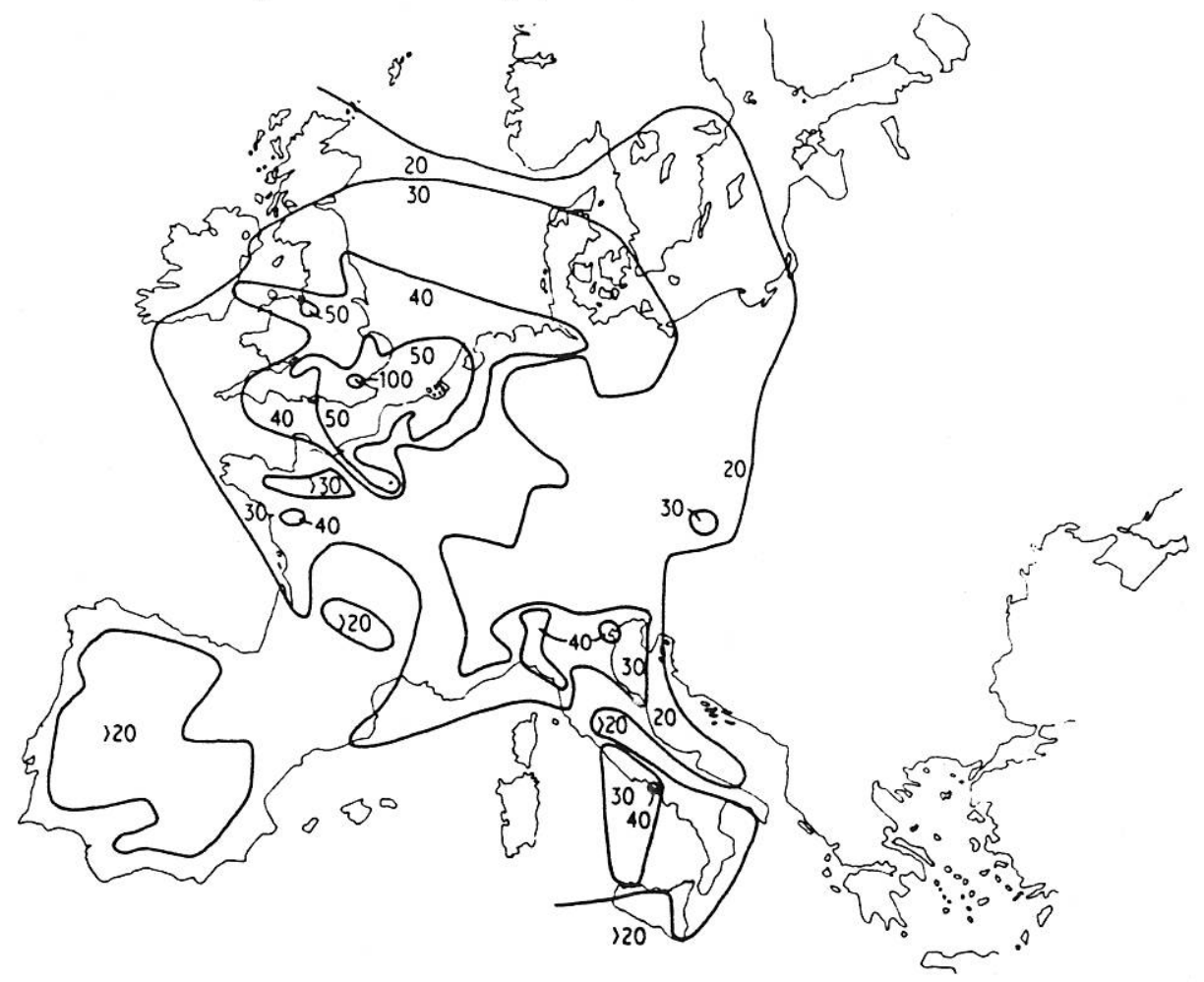

Urban potential in Europe, 1800

The migration of the maximum value of urban population potential is a test of Braudel's hypothesis about the shift of world-economy centres.

Source : De Vries, 1984. 
Figure 3 Relativity of geographical space perception

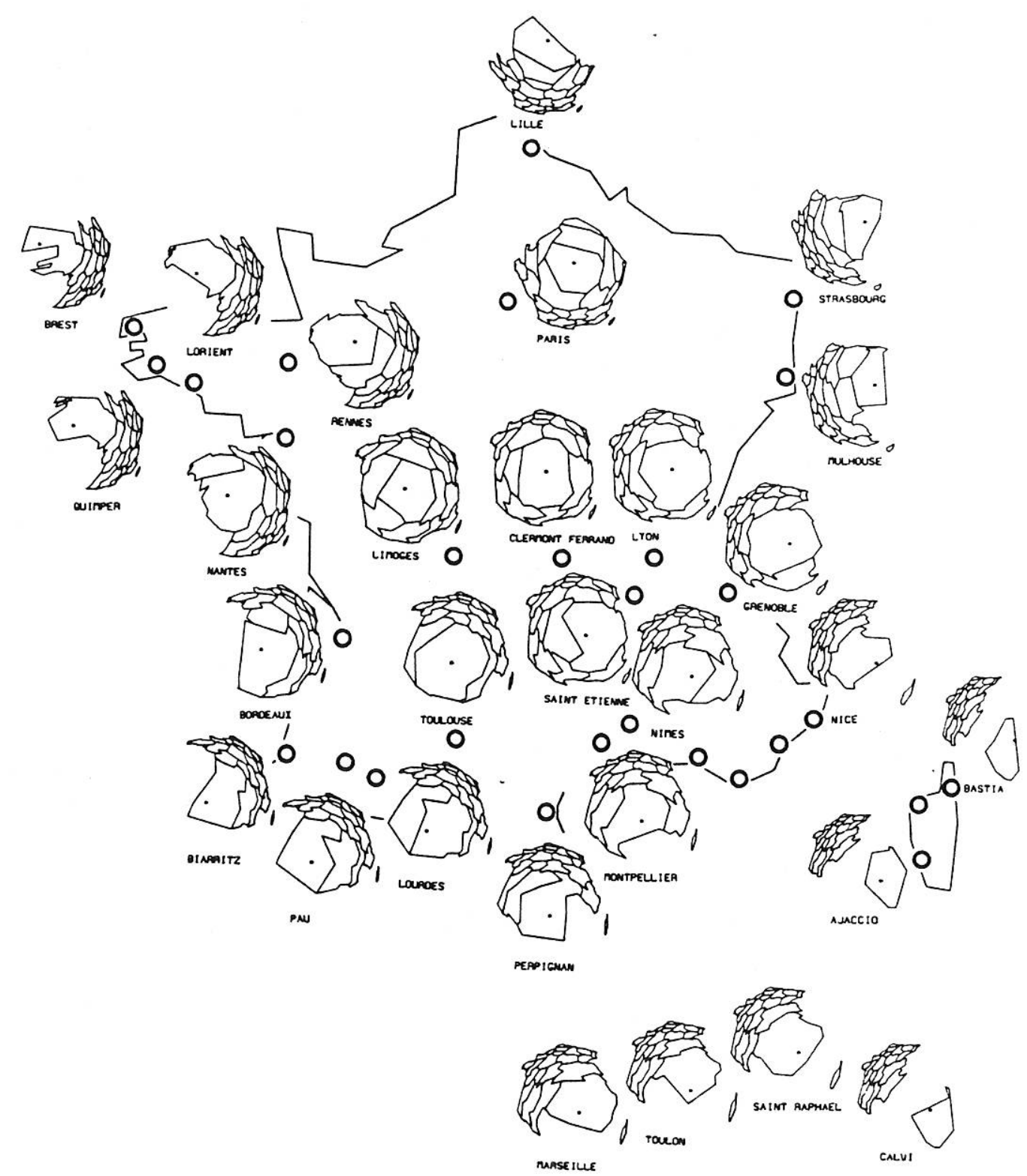

What does France look like from each airport?

Source : Rimbert, 1991. 
Figure 4 Hierarchical structure of geographical space

\begin{tabular}{|c|c|c|c|}
\hline \multirow{2}{*}{ Order } & \multicolumn{2}{|c|}{ Internal area } & \multirow{2}{*}{ External area } \\
\hline & Inner & Outer & \\
\hline $\begin{array}{l}\text { I. Establishnent....... } \\
\text { Example: } \\
\text { Farm }\end{array}$ & Farmstead & Fields & $\begin{array}{l}\text { One-step bi-pclar inter. } \\
\text { connections outside the } \\
\text { establishment } \\
\end{array}$ \\
\hline $\begin{array}{l}\text { II. Focal Place.......................... } \\
\text { Example: } \\
\text { Boswell. Ind. }\end{array}$ & $\begin{array}{l}\text { Built-up area of the } \\
\text { town }\end{array}$ & $\begin{array}{l}\text { Service area of primary } \\
\text { focus }\end{array}$ & $\begin{array}{l}\text { One-step bi-polar inter- } \\
\text { connections outside the } \\
\text { area of primary focus }\end{array}$ \\
\hline $\begin{array}{l}\text { III. Cluster of Focal Places } \ldots \ldots \ldots \ldots \ldots \\
\text { Example: } \\
\text { Kankakee. III. }\end{array}$ & $\begin{array}{l}\text { Contiguous cluster of } \\
\text { neighborhoods }\end{array}$ & $\begin{array}{l}\text { Non-contiguous cluster } \\
\text { of focal places }\end{array}$ & $\begin{array}{l}\text { One-step bi-polar inter. } \\
\text { connections outside the } \\
\text { areas of primary focus }\end{array}$ \\
\hline $\begin{array}{l}\text { IV. Central Place........... } \\
\text { Example: } \\
\text { South Bend, Ind. }\end{array}$ & $\begin{array}{l}\text { Contiguous and non- } \\
\text { contiguous cluster of } \\
\text { focal places socused on } \\
\text { fourth-order center }\end{array}$ & $\begin{array}{l}\text { Non-contiguous clus- } \\
\text { ters of iocal places of } \\
\text { third order }\end{array}$ & $\begin{array}{l}\text { One-step bi-pilar inter. } \\
\text { connections outside the } \\
\text { areas of primary focus }\end{array}$ \\
\hline $\begin{array}{l}\text { V. Hub of a Group of Central Places... } \\
\text { Example: } \\
\text { Chicago. III." }\end{array}$ & $\begin{array}{l}\text { Contiguous or non- } \\
\text { contiguous cluster of } \\
\text { central places focused } \\
\text { on a fifth-order center }\end{array}$ & $\begin{array}{l}\text { Non-contiguous group } \\
\text { of fourth order central } \\
\text { places }\end{array}$ & $\begin{array}{l}\text { One-step bi-polar inter- } \\
\text { connections outside the } \\
\text { areas of primary focus }\end{array}$ \\
\hline
\end{tabular}

*Chicago is also a sixth-order place. All other examples given are cities in the tighest position in the hierarchy which they attain.

Source : A.K. Philbrick, 1957.

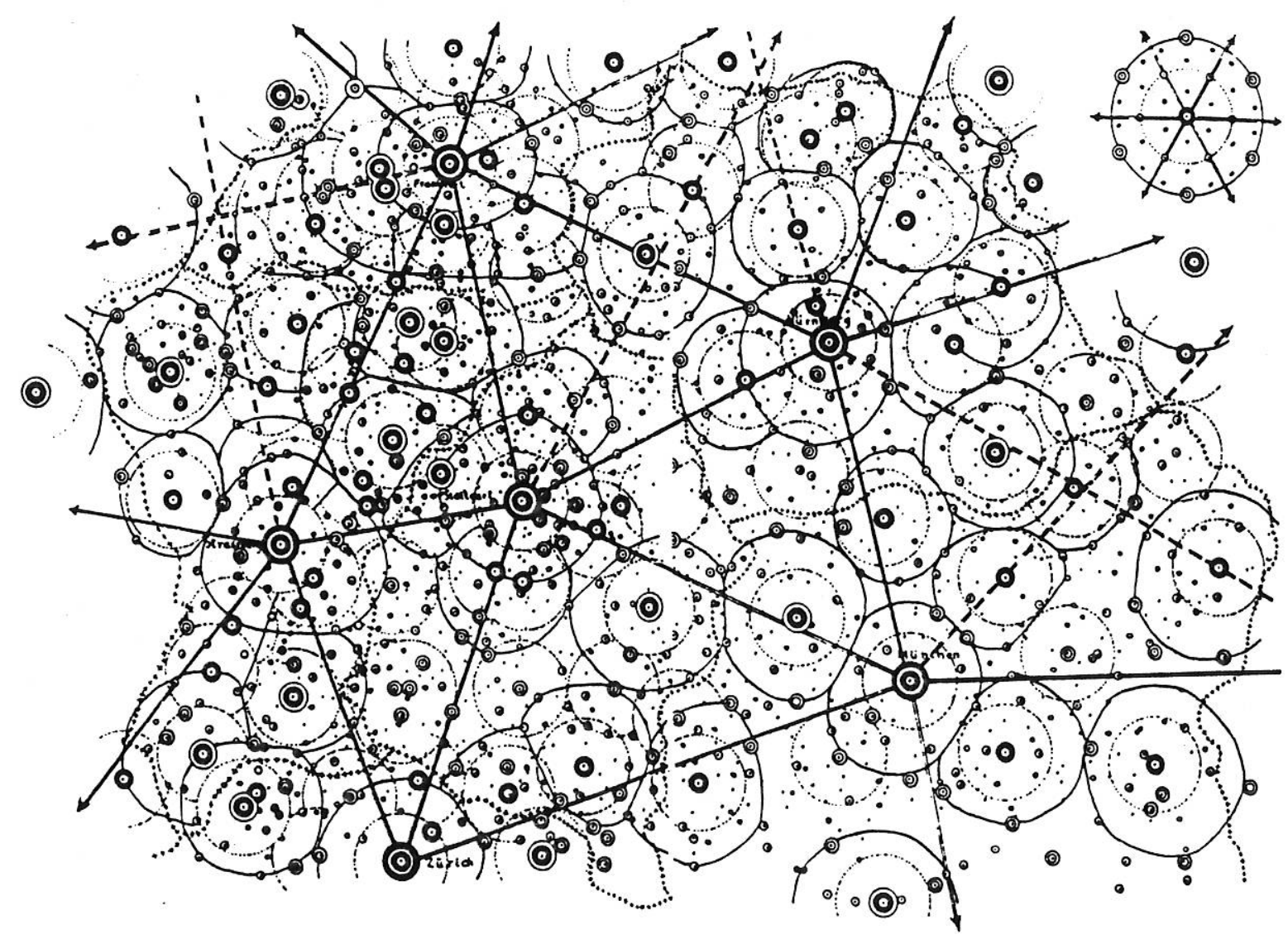

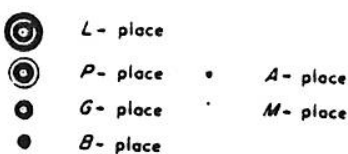

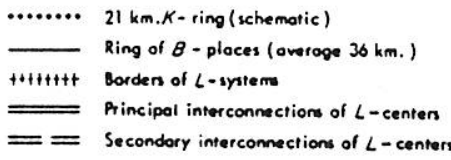

Distribution of Central Places in the South of Germany

Source : W. Christaller, 1933. 
Figure 5 Space-time contraction

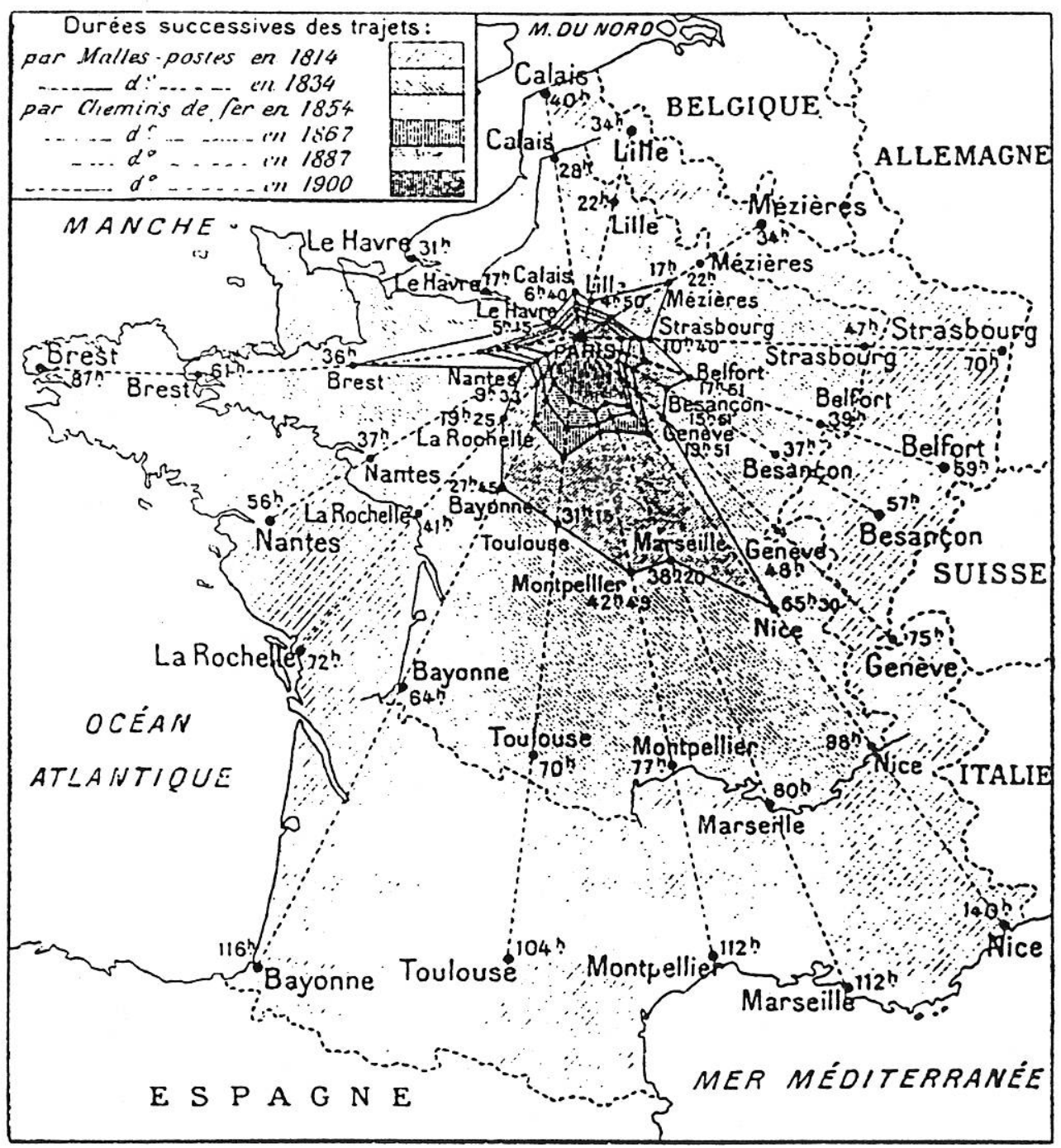

Source : J. Bruhnes, 1910. 
Figure 6 Stability of city size distribution

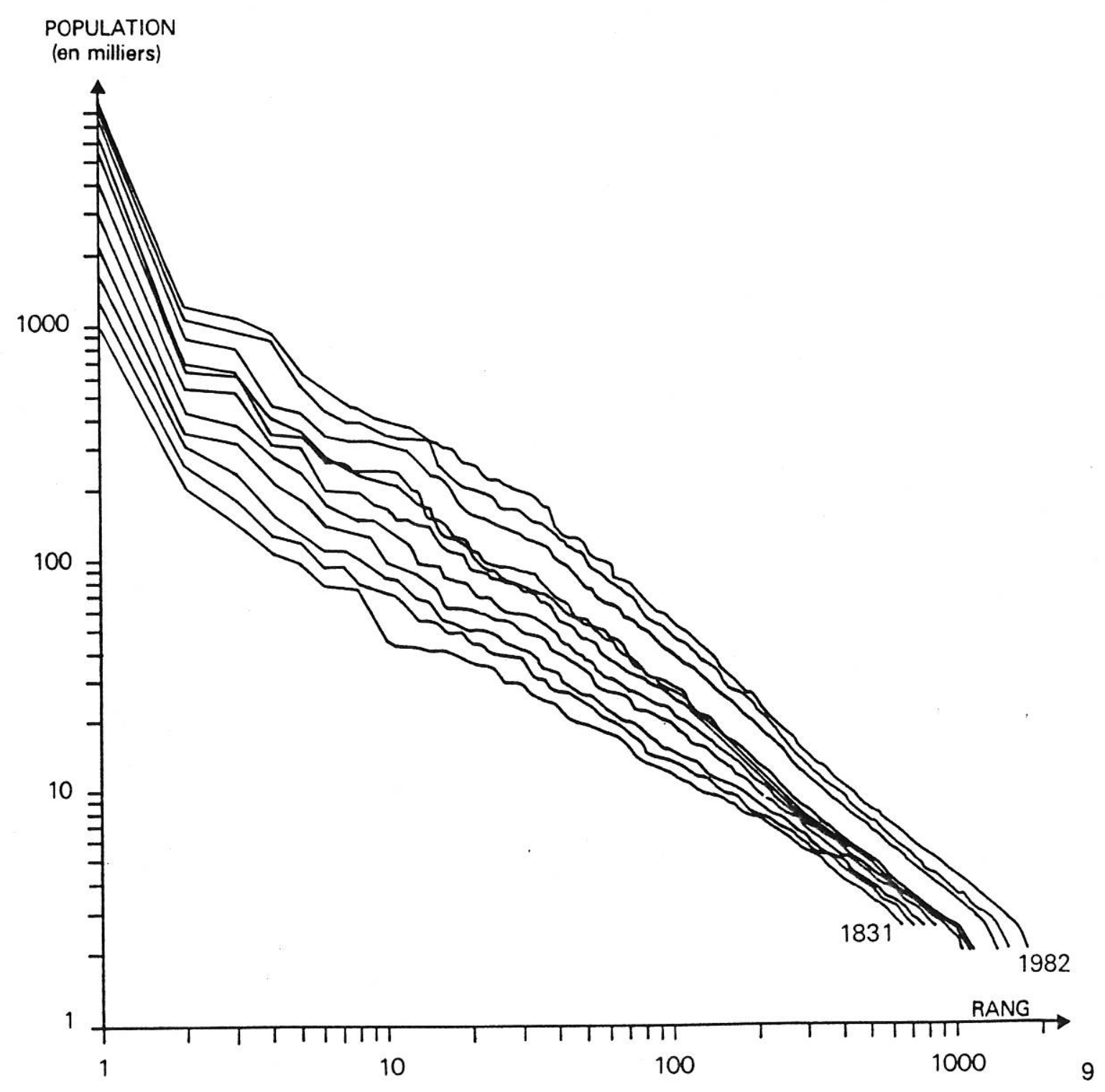

Source : F. Guérin, 1990. 
Figure 7 Elementary geographical structures

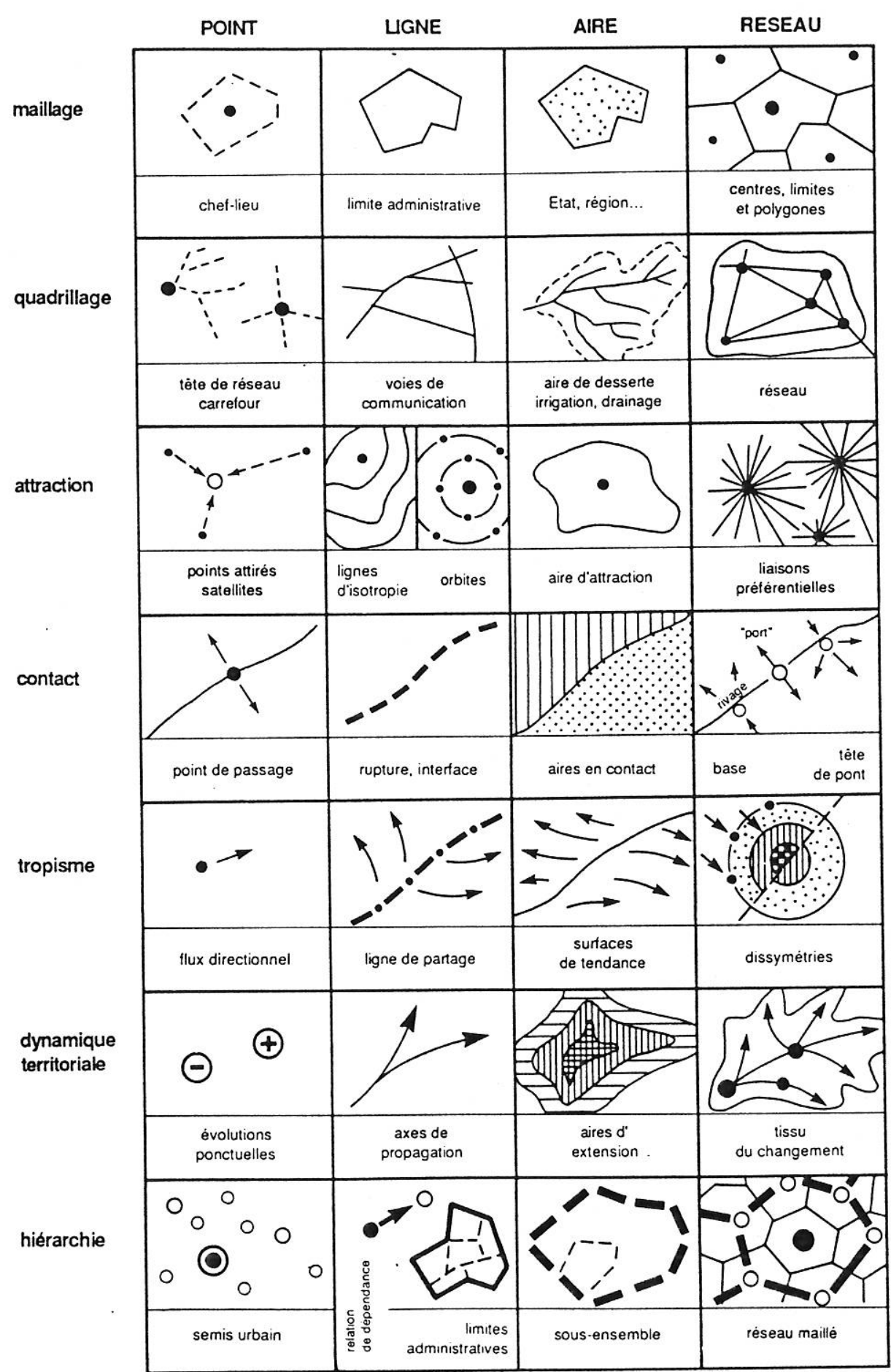

Source : R. Brunet, 1980. 